\title{
Old Treatment for a New Disease: Can Rectal Ozone Insufflation Be Used for COVID-19 Management? A Case Report
}

\author{
Hamdy A. Hendawy ${ }^{1} \cdot$ Walid Mosallam $^{1} \cdot$ Mohamed E. Abuelnaga ${ }^{1}$ (D) Amr M. Sabry ${ }^{1}$
}

Accepted: 7 April 2021 / Published online: 14 April 2021

(C) The Author(s), under exclusive licence to Springer Nature Switzerland AG 2021

\begin{abstract}
COVID-19 is a newly discovered deadly disease with no proven definitive treatment until now. It is now proved that it can affect different body organs which necessitate intensive care management. Ozone (O3) therapy was used before for treating various viral infections like hepatitis B, human immune deficiency virus (HIV), and Ebola viruses. O3 also can manage hypoxia and increase tissue oxygenation, besides its anti-inflammatory and immunomodulatory properties which may have an important role in the management of cytokine storm. We used rectal $\mathrm{O} 3$ insufflation therapy assuming that it may have a beneficial role in the management of COVID-19 disease. Two sessions of rectal O3 therapy were given to a 60-year-old female patient who was confirmed COVID-19 positive. Before applying O3 therapy, she was hypoxic (sPO2:90\%) despite mechanical ventilation with high fraction inspired oxygen (FiO2:90\%). After therapy, she was markedly improved and discharged to the inpatient ward and then discharged home on day 10 post-admission. Another 40-year-old male patient who was confirmed COVID-19 positive and was home isolated received one session of 33 therapy. Before therapy, he was hypoxic (sPO2:85\% on room air and $95 \%$ with $\mathrm{O} 2$ face mask $5 \mathrm{~L} / \mathrm{min}$ ). The patient showed gradual improvement over the next 3 days after therapy and becomes oxygenindependent (sPO2 became $94-97 \%$ on room air). No adverse effects were noticed in both cases. Rectal O3 insufflation can be used safely as adjuvant management for patients with COVID-19 disease.
\end{abstract}

Keywords COVID-19 · Cytokine storm · Ozone therapy

\section{Introduction}

Since its detection at the end of 2019, the SARS-CoV-2 coronavirus has infected more than 129 million people worldwide, causing mortality for over 2.8 million patients [1].

This article is part of the Topical Collection on Covid-19

Mohamed E. Abuelnaga

Mohamed_abuelnga@med.suez.edu.eg

Hamdy A. Hendawy

hamdyhendawy@gmail.com

Walid Mosallam

walidmosallam@yahoo.com

Amr M. Sabry

amro_sabry88@yahoo.com

1 Faculty of Medicine, Suez Canal University, P.O. Box: 41522, The ring road, Ismailia City, Egypt
Initially, the disease COVID-19 was thought to affect primarily the respiratory system, but now it is well known that it is a complex disease that can affect other body systems like the heart, brain, and kidneys, increasing the need for intensive care management. Following transmission, the virus infects the cells of the nasal or oral epithelium, binding with the angiotensin-converting enzyme-2 (ACE2) receptor by its spike protein. Virus-receptor binding enables viral replication by injecting its nucleocapsid inside the cells [2]. The majority of patients with COVID-19 disease have self-limited mild to moderate symptoms in the form of upper respiratory tract infection together with fatigue and muscle aches. In the critically affected patients, a cytokine storm was noticed to be found, characterized by the extreme immune response with increased amounts of pro-inflammatory cytokines (like interleukins and tumor necrosis factor (TNF)- $\alpha$ ) and chemokines [3]. Seventy-five percent of patients are presented with bilateral peripheral viral pneumonia, whether pleural effusion, pulmonary nodules, and lymphadenopathy are found in less than $5 \%$ of patients [4]. Patients usually show tachypnea without 
dyspnea, marked hypoxemia, and ventilation-perfusion mismatching but with no change in lung compliance [5]. After 15 days of the onset of symptoms, a small percentage of patients can progress to a more severe form of pulmonary disorder due to cytokine storm. Extreme levels of proinflammatory cytokines and chemokines will induce lung damage in the form of alveolar cell desquamation, the formation of hyaline membranes, and pulmonary edema, leading to progression to the full picture of acute respiratory distress syndrome (ARDS) and respiratory failure [4]. This stage is characterized by low lung compliance and right-to-left shunting [5]. Till now there is no identified final treatment for COVID-19 disease. In a recent review article, Fernández-Cuadros et al. reported that $\mathrm{O} 3$ could be beneficial for the management of COVID-19 disease, due to its virucidal, immunomodulatory properties, as well as its ability to facilitate oxygen transport to hypoxemic tissues [6]. Interestingly, Manjunath et al. have investigated recent case reports on the use of $\mathrm{O} 3$ to combat coronavirus, and concluded that it could be advantageous in combating coronaviruses in the human body as well as in the environment [7]. The effectiveness of rectal $\mathrm{O} 3$ insufflation was evaluated in a recent study that included four patients with severe COVID-19 pneumonia. Improved oxygen saturation was noted after 5 sessions of treatment, together with reduced levels of biomarkers of inflammation [8]. In the following cases, we used O3 therapy as a potential treatment, based on our knowledge about its ability to treat hypoxia and its antiviral properties. Of note, this manuscript adheres to the applicable EQUATOR guidelines. Informed written consent was obtained from all participant patients and they were informed that data from the case would be submitted for publication.

\section{Case Reports}

\section{Case 1}

A 60-year-old female hypertensive patient, obese with body mass index $30 \mathrm{~kg} \mathrm{~m}^{-2}$, was confirmed COVID-19 positive. She was home quarantined for 6 days. On day 7, the patient presented to the emergency room with fever, dyspnea, and tachypnea. Initial assessment showed temperature: $38^{\circ} \mathrm{C}$; respiratory rate $(\mathrm{RR}): 50$ cycles $\mathrm{min}^{-1}$; heart rate (HR): 120 beats $\min ^{-1}$; and arterial oxygen saturation (sPO2): $60 \%$ on room air. After the failure of a non-rebreathing face mask to achieve sufficient oxygen saturation, the patient was attached to continuous positive airway pressure (CPAP) in the intensive care unit (ICU) with fraction inspired oxygen (FiO2): $90 \%$ with progressive improvement of sPO2 till reaching $90 \%$. A session of rectal O3 therapy was done. Two liters of oxygen-Ozone $(\mathrm{O} 2 / \mathrm{O} 3)$ gas mixture with a concentration of $12.6 \mu \mathrm{g} \mathrm{mL}^{-1}(25.2 \mathrm{mg})$ was injected slowly into the rectum by a previously inserted catheter. Abdominal and pelvic X-ray was done and showed gaseous distention of the colon down to the cecum (Fig. 1). After $2 \mathrm{~h}$ sPO2 started to improve gradually till reaching $96 \%$, with heart rate slowing down to 95 beats $\min ^{-1}$ after $4 \mathrm{~h}$ of $\mathrm{O} 3$ therapy. After $24 \mathrm{~h}$, the patient was weaned from the CPAP and Venturi face mask, FiO2 $60 \%$ was applied with sPO2 94\%, RR 28 cycles $\min ^{-1}$ and HR 90 beats $\min ^{-1}$. After $48 \mathrm{~h}$ from the first $\mathrm{O} 3$ session, we noticed a gradual improvement of the patient, $\mathrm{SpO} 2$ was $94 \%$ with venturi $\mathrm{O} 2$ mask $50 \%$, RR was 28 cycles min $^{-1}$, and HR 94 beats $\min ^{-1}$. Pelvic and abdominal X-ray was repeated and showed an empty colon so we decide to give her another session of $\mathrm{O} 3$. The patient started to improve gradually over the next 2 days, and finally, sPO2 was 95\%, HR 84 beats $\min ^{-1}$, and RR 16 cycles $\min ^{-1}$ with supplemental oxygen $28 \%$ with Venturi mask. The patient was discharged to the inpatient isolation ward then discharged home by day 16 with no adverse effects.

\section{Case 2}

A 40-year-old male with no history of chronic illness, obese with BMI 32, was quarantined at home after being confirmed COVID-19 positive. His main complaint was fever, sore throat, body aches, and dry cough. He was taking regularly vitamin $\mathrm{C}$, zinc, vitamin $\mathrm{D}$, and paracetamol $1 \mathrm{~g}$ every $8 \mathrm{~h}$ for control of fever (oral temperature ranges from 38 to $38.5^{\circ} \mathrm{C}$ ).

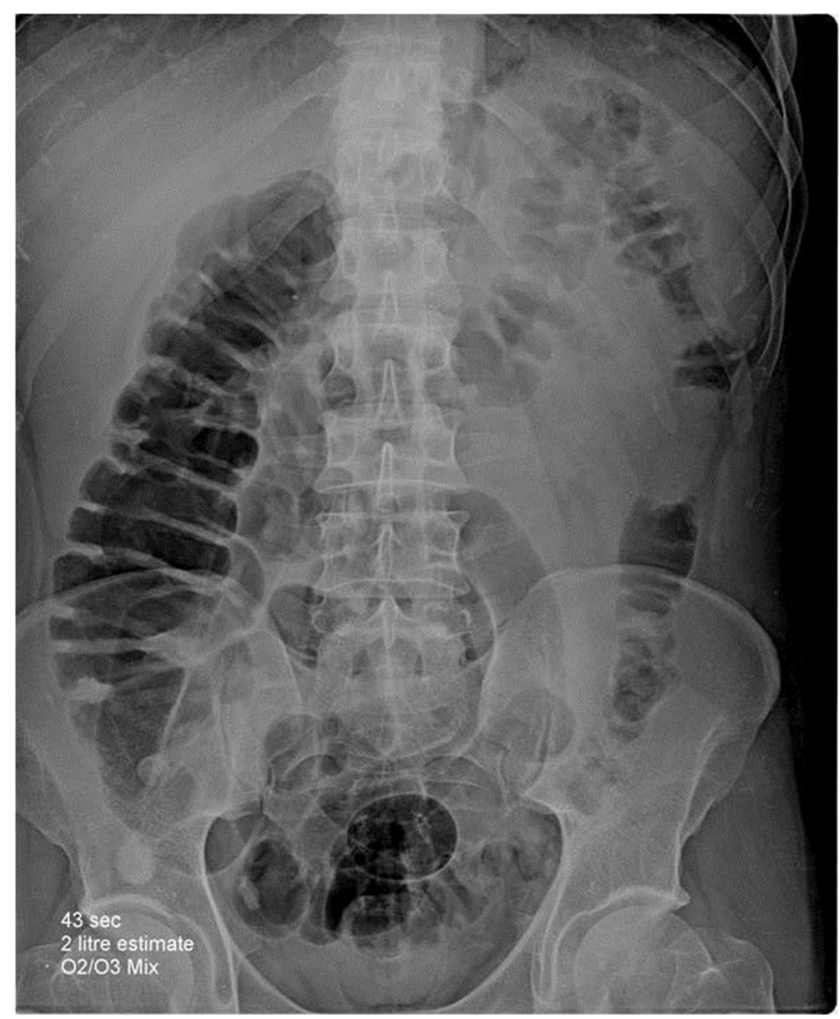

Fig. 1 Pelvi-abdominal X-ray after rectal insufflation of $2 \mathrm{~L}$ of ozone 
After 11 days of the onset of symptoms, he was presented to the emergency room with dyspnea and tachypnea. $\mathrm{SpO} 2$ was $85 \%$ on room air, RR 30 cycles $\min ^{-1}$, and HR 110 beats $\min ^{-1}$. Simple $\mathrm{O} 2$ face mask $5 \mathrm{~L} \mathrm{~min}^{-1}$ was applied with improvement of $\mathrm{SpO} 2$ reaching $95 \%$. The potential benefits of $\mathrm{O} 3$ therapy were explained to him. After taking written consent, the patient received $25.2 \mathrm{mg}$ of $\mathrm{O} 3$ by rectal insufflation. The patient continued his home isolation with home oxygen therapy because of the unavailability of beds in the isolation hospital. We asked his wife to monitor and record his $\mathrm{SpO} 2$ every hour using a portable pulse oximeter, and to supplement him with $\mathrm{O} 2$ via face mask if $\mathrm{SpO} 2$ is less than $95 \%$. We advised her to contact us by phone in case of any deterioration. After $4 \mathrm{~h}$ of $\mathrm{O} 3$ therapy, the patient's $\mathrm{SpO} 2$ showed marked improvement, and the patient did not require oxygen therapy, $\mathrm{SpO} 2$ was $95 \%$ on room air, RR was 17 cycles $\min ^{-1}$, and heart rate was 94 beats $\mathrm{min}^{-1}$. Over the next 3 days, $\mathrm{SpO} 2$ ranged from 94 to $97 \%$ without oxygen supplementation with marked improvement of fever and body aches. No adverse effects were noticed.

\section{Discussion}

$\mathrm{O} 3$ is a colorless gas that can dissolve easily in water according to Henry's law. Its half-life in the body is milliseconds, while it produced metabolites with longer half-life named ozonides. Ozonoides which include reactive oxygen species and products of lipid oxidation are proven to mediate the immunomodulatory effects of ozone. The therapeutic potency of ozone relies on the oxidative stress produced by its interactions with different biological components [9].

Viruses can be vulnerable to ozone, specifically, lipidenveloped viruses like coronaviruses. This lipid envelop is rich in cysteine and contains a thiol or sulfhydryl group that enables viral cell entry and fusion [10]. Peroxides generated by $\mathrm{O} 3$ have antiviral effects by its ability to oxidize sulfhydryl groups as well as cysteines, leading to reduced viral load [11].

Some studies proposed that $\mathrm{O} 3$ can augment the phagocytic activity of neutrophils [12], normalize the inflammatory response and the immune response to infection [13], and induce the release and modulation of interferons and some antiinflammatory cytokines (IL-4, IL-6, IL-10, TNF) [14].

Several studies have shown the usefulness of $\mathrm{O} 3$ in the management of many viral diseases. Cespedes et al. [15] have used $\mathrm{O} 3$ for the treatment of chronic hepatitis B infection. They found favorable results concerning normalization of hepatic transaminase levels, the negativity of viral surface antigen, with the positivity of antibodies against the surface antigen. O3 therapy has shown favorable results in decreasing viral load in AIDS patients with increased levels of CD4 and CD8 [16]. Ebola virus which looks like COVID-19 in causing a cytokine storm was successfully treated in 5 patients with O3 according to Robert Jay et al. [17].

From our point of view, the most beneficial therapeutic effect of O3 therapy, in COVID-19 patients, is its ability to reverse hypoxemia and hence increasing tissue oxygenation. O3 was found to increase 2-3 diphosphoglycerate levels with successive stimulation of glycolysis and elevation of energy levels through increased ATP. This will shift the oxy-hemoglobin dissociation curve to the right side, helping red blood cells to maintain and improve tissue oxygenation [9].

This effect could be matched with the result seen in the case report described by Peña-Lora and his colleagues about an 84year-old woman diagnosed with SARS-CoV-2 infection. She is known to have chronic obstructive pulmonary disease with chronic home oxygen, and pulmonary nodule with malignant criteria. She did not show any improvement with the medical management based on the clinical guidelines of COVID-19 pneumonia, while marked improvement of oxygenation was noticed after 5 sessions of rectal O3 therapy [18].

The most popular method of $\mathrm{O} 3$ therapy is the major autohemotherapy. It consists of extracorporeal ozonation of $50-225 \mathrm{~mL}$ of the patient's venous blood by mixing it with a mixture of $\mathrm{O} 2 / \mathrm{O} 3$ at concentrations of $15-70 \mu \mathrm{g} \mathrm{mL}^{-1}$. The ozonated blood is then turned back into the body by intravenous transfusion [9].

Rectal insufflation O3 therapy was used safely with a dose range from 0.2 to $79 \mathrm{mg} \mathrm{kg}^{-1}$ bodyweight, a concentration between 10 and $50 \mu \mathrm{g}$, and volume up to $300 \mathrm{~mL}$ without reported side effects [19]. With our patients, we used the rectal insufflation method which is more easily applicable, safe, and effective and did not need special training. We found that small volumes did not produce fast improvement of oxygenation so we decided to use a high volume of $\mathrm{O} 3$ as tolerated by the patients and guided by $\mathrm{X}$ ray as we believe that this will increase the surface area available for absorption with the probability of better results. Our target was to fill the whole colon with the gas mixture of $\mathrm{O} 2 / \mathrm{O} 3$. Improvement of oxygenation in our cases was faster than described in cases that received small volumes of $\mathrm{O} 3$ [8]. More research work is needed to determine the best volume and concentration of rectal $\mathrm{O} 3$ therapy for patients with COVID-19 pneumonia.

\section{Conclusion}

Ozone was used safely in COVID-19 patients with a rapid improvement of oxygen saturation with no side effects. We believe that further studies are required to investigate the possibility of ozone therapy as a potential treatment for COVID-19 disease as well as investigating different volumes and doses. 


\section{Clinical Relevance}

- COVID-19 is a complex disease that can affect the whole body systems causing multi-organ failure in severe cases.

- The hallmark of COVID-19 disease is hypoxemia and cytokine storm.

- Ozone therapy can be used for ameliorating the severity of COVID-19 disease.

Abbreviations HIV, Human immune deficiency virus; ACE2, Angiotensin converting enzyme 2; TNF, Tumor necrosis factor; ARDS, Acute respiratory distress syndrome; O3, Ozone; RR, Respiratory rate; HR , Heart rate; $\mathrm{sPO} 2$, Arterial oxygen saturation; CPAP, Continuous positive airway pressure; ICU, Intensive care unit; FiO2, Fraction inspired oxygen

Acknowledgements We would like to thank all participant patients in our study, our colleagues, and the nursing staff in Suez Canal University Hospital.

Author contribution 1. Hamdy A. Hendawy MD: This author helped in preparing the concept of the research, design, clinical work, data acquisition, and final editing of the paper.

2. Walid Mosallam, MD: This author helped in the definition of intellectual content, literature search, clinical work, manuscript review, and manuscript editing.

3. Mohamed E. Abuelnaga, MD: This author helped in literature search, clinical work, manuscript preparation, and manuscript review.

4. Amr M. Sabry, M.Sc: This author helped in literature search, clinical work, and data acquisition.

\section{Declarations}

Conflict of Interest The authors declare no competing interests.

Informed Consent Informed written consent was done for all patients participating in the study.

\section{References}

1. Hopkins J. COVID-19 Map. 2020. https://coronavirus.jhu.edu/ map.html. Accessed 1st April 2021.

2. McKee DL, Sternberg A, Stange U, Laufer S, Naujokat C. Candidate drugs against SARSCoV-2 and COVID-19. Pharmacol Res. 2020;157:104859.

3. Mehta P, McAuley DF, Brown M, Sanchez E, Tattersall RS, Manson JJ. COVID-19: consider cytokine storm syndromes and immunosuppression. Lancet. 2020;395(10229):1033-4.
4. Shi H, Han X, Jiang N, Cao Y, Alwalid O, Gu J, et al. Radiological findings from 81 patients with COVID-19 pneumonia in Wuhan, China: a descriptive study. Lancet Infect Dis. 2020;20(4):425-34.

5. Gattinoni L, Chiumello D, Caironi P, et al. COVID-19 pneumonia: different respiratory treatments for different phenotypes? Intensive Care Med. 2020:1099-102.

6. Fernández-Cuadros ME, Albaladejo-Florín MJ, Peña-Lora D, Álava-Rabasa S, Pérez-Moro OS. Ozone (O3) and SARS-CoV-2: physiological bases and their therapeutic possibilities according to COVID-19 evolutionary stage. SN Compr Clin Med. 2020:1-9.

7. Manjunath SN, Sakar M, Katapadi M, Balakrishna RG. Recent case studies on the use of ozone to combat coronavirus: problems and perspectives. Environ Technol Innov. 2020;21:101313.

8. Fernández-Cuadros ME, Albaladejo-Florín MJ, Álava-Rabasa S, Usandizaga-Elio I, Martinez-Quintanilla Jimenez D, Peña-Lora D, et al. Effect of rectal ozone (O 3) in severe COVID-19 pneumonia: preliminary results. SN Compr Clin Med. 2020;2(9):1328-36.

9. World Federation of Ozone Therapy Review on Evidence-Based Ozone Therapy (WFOT). WFOT Scientific Advisory Committee 2015. Link: https://bit.ly/2XGbeij

10. Madu IG, Belouzard S, Whittaker GR. SARS-coronavirus spike S2 domain flanked by cysteine residues C822 and C833 is important for activation of membrane fusion. Virology. 2009;393:265-71.

11. Dussault PH, George AD, Trullinger TK. Peroxides as oxidative enzyme inhibitors: mechanism-based inhibition of a cysteine protease by an amino acid ozonide. Bioorg Med Chem Lett. 1999;9: 3255-8.

12. Diaz LJ, Menendez CS, Diaz LA, Ascanio GY. In vitro effect of ozone in phagocytic function of leucocytes in peripheral blood. J Ozone Ther. 2015;1:4.

13. Hayden MS, West AP, Ghosh S. NF-kappaB and the immune response. Oncogene. 2006;25:6758-80.

14. Bocci V, Borrelli E, Travagli V, Zanardi I. The ozone paradox: ozone is a strong oxidant as well as a medical drug. Med Res Rev. 2009;29:646-82.

15. Cespedes SJ, Martin SY, Carballosa PMR, Dager CDR. Response of patients with chronic Hepatitis B in one year of treatment with major autohemotherapy. J Ozone Ther. 2018;2(3):1-7.

16. Cespedes SJ, Martin SY, Carballosa PMR, Dager CDR. The immune response behavior in HIV-AIDS patients treated with ozone therapy for two years. J Ozone Ther. 2018;2(3).

17. Rowen RJ, Robins H, Carew K, Kamara MM, Jalloh MI. Rapid resolution of hemorrhagic fever (Ebola) in Sierra Leone with ozone therapy. Afr J Infect Dis. 2016;10(1):49-54.

18. Peña-Lora DY, Albaladejo-Florín MJ, Fernández-Cuadros ME. Usefulness of rectal ozonetherapy in a geriatric patient with severe COVID-19 pneumonia. Revista Espanola de Geriatria y Gerontologia. 2020;55(6):362-4.

19. Martinezs G, Re L. Rectal administration and its application in ozonetherapy. Int J Ozone Ther. 2012;11:41-9.

Publisher's Note Springer Nature remains neutral with regard to jurisdictional claims in published maps and institutional affiliations. 